\title{
RELEVO E FERTILIDADE DO SOLO EM DIFERENTES ESTRATOS DA COBERTURA VEGETAL NA BACIA HIDROGRÁFICA DA REPRESA VACA BRAVA, AREIA, PB ${ }^{1}$
}

\author{
Antonio Clementino dos Santos² e Ignácio Hernan Salcedo ${ }^{3}$
}

\begin{abstract}
Resumo - Este trabalho foi realizado na Mesorregião do Agreste da Borborema, em uma área de 1.404 ha, correspondente à bacia hidrográfica da represa Vaca Brava, em Areia, PB. Para avaliar relevo e fertilidade do solo, 360 amostras simples de solo $(0-20 \mathrm{~cm})$ dessa bacia hidrográfica, representando combinações de quatro usos do solo e cinco posições no relevo, foram analisadas. As propriedades químicas estudadas foram: carbono, nitrogênio, fósforo, potássio, cálcio, magnésio e pH. Com relação às propriedades físicas, avaliaram-se a granulometria e densidade do solo. Pela análise descritiva, constatou-se que os dados de densidade do solo e pH foram os que menos variaram, enquanto o fósforo, potássio e magnésio apresentaram as maiores variações. As propriedades químicas e físicas mostraram-se influenciadas pelo uso do solo, com aumento nos teores no sentido agriculturafloresta. Entretanto, em relação ao fósforo disponível, a variabilidade ocorreu no sentido contrário.
\end{abstract}

Palavras-chave: Agricultura-floresta, Química do solo e Propriedade física.

\section{LANDFORM AND SOIL FERTILITY IN DIFFERENT STRATA OF VEGETATIVE COVERING OF VACA BRAVA WATERSHED, AREIA - STATE OF PARAÍBA}

\begin{abstract}
SUMMARY - This study was conducted in the mesoregion of Agreste de Borborema, an area of 1404 ha corresponding to the Vaca Brava watershed - Areia City, State of Paraíba, Brazil. Three hundred and sixty soil samples $(0-20 \mathrm{~cm})$, representing combinations of four land uses and five positions in the relief were collected from the Vaca Brava watershed and its relationships were studied. The chemical components: carbon, nitrogen, phosphorus, potassium, calcium, magnesium, and $\mathrm{pH}$ were analyzed. Regarding physical properties, soil granulometry and density were analyzed. Descriptive analysis of soil density and $\mathrm{pH}$ showed the smallest variations. Phosphorus, potassium and magnesium presented the largest variations. Thus, chemical and physical properties revealed to be influenced by soil use, showing increasing values compared to agriculture-forest landforms, although available phosphorus presented opposite variation.
\end{abstract}

Keywords: Agriculture-forest, Soil chemistry and Soil physical properties.

\section{INTRODUÇÃO}

Um dos principais fatores que atuam na composição e estrutura dos ecossistemas é a heterogeneidade ambiental. Essa heterogeneidade é o resultado da diversidade de fatores que interagem nas comunidades, e a resposta das espécies a esses fatores faz que cada local tenha características próprias e características que são comuns a outros locais, possibilitando observar tendências (RODRIGUES et al., 2007). O tema é composto por complexa malha de ação antrópicas, que responsabiliza a atividade da agropecuária como um dos principais agentes supressores da floresta.

Acerca dessa perspectiva existe a necessidade de buscar alternativas que promovam o desenvolvimento regional, mas sem perder de vista as considerações sobre a sustentabilidade, de forma que o solo seja considerado recurso natural renovável.

\footnotetext{
${ }^{1}$ Recebido em 10.05.2008 e aceito para publicação em 14.10.2009.

${ }^{2}$ Universidade Federal do Tocantins, UFT, Brasil. E-mail: <clementino@uft.edu.br>.

${ }^{3}$ Universidade Federal de Pernambuco, UFPE, Brasil. E-mail: <salcedo@ufpe.br>.
} 
Uma área de extrema importância devido a fatores bióticos ou abióticos, mas pouco estudada, é a vegetação Floresta Atlântica de altitude. Ela abrange atualmente pequenos fragmentos florestais na Região Nordeste do Brasil. Esse tipo de vegetação desempenha relevante importância na manutenção da integridade dos ecossistemas locais, representando importante área de preservação de espécies animais e vegetais e conservação dos recursos naturais. Porém, mesmo protegidas por legislação ambiental específica, essas formações foram e continuam sendo alteradas, principalmente por atividades antrópicas. As atividades agropecuárias associadas ao uso de queimadas e extrativismo florestal são apontadas como as principais causas da fragmentação florestal e degradação dos ecossistemas associados às bacias hidrográficas (PAINE e RIBIC, 2002).

Considerando que o solo é a base para agricultura e produção florestal sustentável, é necessário adotar práticas de manejo que conservem e, ou, restaurem sua fertilidade, a fim de manter a produtividade (ALVARENGA, 1996). O uso intenso das terras exploradas com culturas perenes ressalta a necessidade de manter exploração racional, para preservar o potencial produtivo dos solos; assim, o conhecimento das propriedades químicas e físicas do solo é ferramenta fundamental para direcionar práticas que reduzam o depauperamento a níveis toleráveis (THEODORO, 1999).

A variação de altitude e a diversidade de formas de relevo de solo determinam a presença de diversas espécies vegetais e de uso. A degradação do solo surge quando se interfere na sua cobertura natural, eliminando-a simplesmente ou substituindo-a por outra cultura. No primeiro caso, o solo fica exposto à erosão, sendo os efeitos dos agentes erosivos mais ou menos intensos, conforme a resistência do solo e a erosividade da chuva e do vento do local. No segundo caso, a degradação do solo pode ser causada tanto pela erosão quanto pela deterioração de suas propriedades por uso e manejo indevidos (SANTOS et al., 2002). O solo, desprovido de cobertura vegetal nas áreas agrícolas preparadas para o plantio, ou com a cobertura vegetal diminuída nos casos de sobrepastejo, sem a ação fixadora das raízes e com o impacto direto da chuva ou do vento, fica exposto aos processos erosivos. Esses processos são mais marcantes nas encostas em função do aumento da declividade.

R. Árvore, Viçosa-MG, v.34, n.2, p.277-285, 2010
Considerando ter sido mais de $90 \%$ da cobertura vegetal da Mata Atlântica já devastada, o plantio tanto de espécies nativas quanto de espécies agroflorestais é importante não só para garantir a recuperação de áreas degradadas, mas também para contribuir com estoque madeireiro alternativo (GARAY et al., 2003). O tipo de solo, o relevo, os sistemas de cultivo e os fatores climáticos também possuem influência na fertilidade do solo (GREGORICH et al., 1998). Quando a topossequência de vegetação nativa é convertida para cultivada, pode haver perda líquida de nutrientes por mineralização ao longo do declive, em decorrência de práticas agrícolas inadequadas, sem planejamento e conhecimento das reais possibilidades de uso do solo. Com a continuação do cultivo, o solo encontra-se suscetível aos processos erosivos, de modo que as áreas convexas das encostas apresentam perdas progressivas de material, enquanto as áreas côncavas atuam inicialmente como áreas de deposição. Entretanto, com a continuidade da erosão as áreas côncavas também sofrem perdas líquidas de nutrientes para outros locais (GREGORICH et al., 1998).

Entre os vários sistemas de usos da terra, as maiores alterações nas características químicas do solo ocorrem sob agricultura tradicional, com capital e nível tecnológico mínimos, e o sistema agroquímico, com alto investimento de capital (ALVARENGA e DAVIDE, 1999). Segundo Weid (1996), do ponto de vista da eficiência agronômica o sistema agroquímico superou todos que o antecederam, embora os resultados não tenham sido homogêneos, comparando os distintos ecossistemas em que foi implantado. Como esse sistema depende intrinsecamente do uso de recursos não renováveis, a questão da sustentabilidade está diretamente vinculada à durabilidade previsível desses recursos. Os solos utilizados para culturas anuais geralmente são os que apresentam maior alteração em relação àqueles sob vegetação nativa (TIESSEN et al., 1992; FRAGA e SALCEDO, 2004).

A produtividade agropecuária da área é influenciada, entre outros fatores, pelas propriedades químicas, físicas e biológicas dos seus solos, ou seja, pela fertilidade deles. Os solos podem ser naturalmente férteis ou se tornarem férteis através de manejo adequado. Para tal, é necessário conhecer e quantificar a variação das propriedades químicas, uma vez que, por serem sistemas dinâmicos e abertos, estão em constantes modificações, constituindo, assim, corpos heterogêneos (SILVA e CHAVES, 2001). 
No estudo da ciclagem de nutrientes, a quantificação das reservas minerais e orgânicas e suas transferências entre compartimentos são de extrema importância para compreender e comparar os diferentes ecossistemas e suas relações com o meio (KURZATKOWSKI et al., 2004). A forma pela qual as árvores efetuam essa ciclagem via serrapilheira é um indicativo da estratégia de adaptação das diferentes espécies às limitações nutricionais de diferentes ambientes (FERREIRA et al., 2001).

A dinâmica da serrapilheira e de seus nutrientes, representada pela entrada via deposição e saída via decomposição/mineralização, é essencial à manutenção de ecossistemas. Em razão disso, nos últimos anos vêm-se observando, na literatura científica, vários trabalhos sobre ecossistemas contendo serrapilheira avaliadas nutricionalmente e seu fracionamento (AIDAR e JOLY, 2003; ARATO et al., 2003; FIGUEIREDO FILHO et al., 2003; SCHUMACHER et al., 2003; BERTALOT et al., 2004; SCHUMACHER et al., 2004).
Como a fertilidade dos solos tropicais depende fortemente da qualidade e quantidade dos estoques orgânicos aportados ao solo, o conhecimento da reconstituição das camadas orgânicas do solo ou horizontes húmicos, relacionados com propriedades edáficas, traz informações relevantes para o futuro manejo desses plantios arbóreos (KINDEL e GARAY, 2002). Nessa perspectiva, o objetivo foi comparar relevo e fertilidade do solo em diferentes estratos da cobertura vegetal em escala de microbacia.

\section{MATERIAL E MÉTODOS}

O trabalho foi realizado na bacia hidrográfica da represa Vaca Brava, localizada na Microrregião do Brejo, na Mesorregião do Agreste, contraposto oriental do Planalto da Borborema, no Estado da Paraíba, Nordeste do Brasil, compreendida entre as coordenadas (UTM) 192000 e 198000 m E e 9225300 e 9231000 m N (Figura 1). Segundo a classificação de Köppen, o clima é do tipo As' "tropical chuvoso"

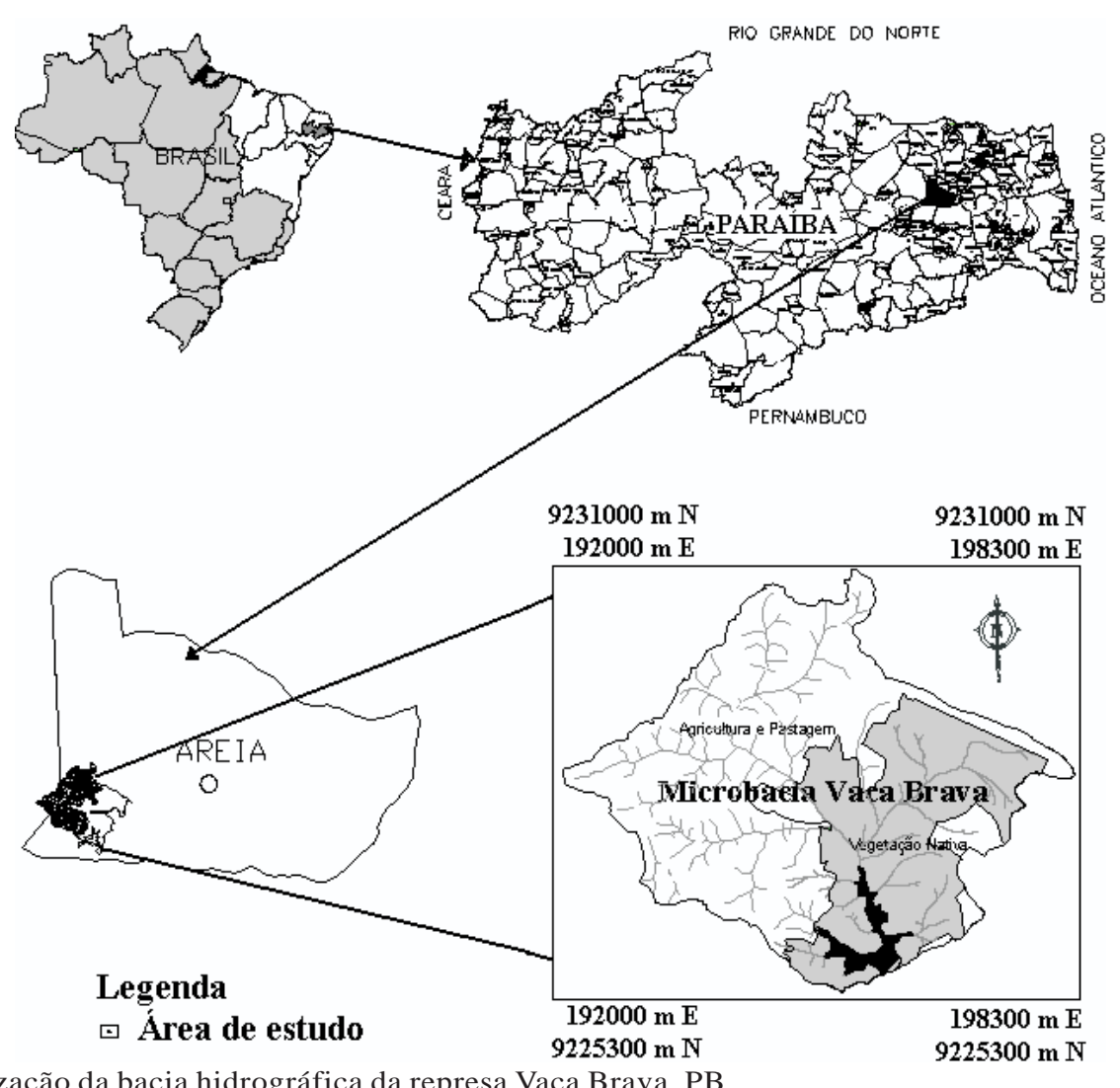

Figura 1 - Localização da bacia hidrográfica da represa Vaca Brava, PB.

Figure 1 - Localization of Vaca Brava Watershed, Paraíba State - Brazil. 
(CHAVES, 1977). A bacia hidrográfica da represa Vaca Brava ocupa uma superfície de 1.500 ha, com altitude média de $637 \mathrm{~m}$ e temperatura média anual de $24^{\circ} \mathrm{C}$, apresentando pequena amplitude de variação (SANTOS et al., 2002). Os solos que predominam na bacia são associação de Argissolo Vermelho Eutroférrico e Neossolo Litólito e, em menor proporção, o Neossolo Regolítico Distrófico e o Latossolo Amarelo Distrófico (EMBRAPA, 1999).

A maior porção da bacia localiza-se quase que inteiramente no Município de Areia e apresenta clima tropical chuvoso (pluviosidade anual de $1.200 \mathrm{~mm}$ ) com chuvas de outono-inverno e déficit hídrico de setembro a janeiro, com relevo ondulado a fortementeondulado. A parte da bacia hidrográfica da represa Vaca Brava que se localiza no Município de Remígio, PB, apresenta características edafoclimáticas de transição, com solos arenosos, relevo suave-ondulado e marcante declínio na pluviosidade anual (820 mm) (SILVA et al., 1993), com déficit hídrico de setembro a fevereiro.

A bacia hidrográfica da represa Vaca Brava apresenta dois tipos de uso da terra predominantes, reserva ecológica (mata nativa) e outro agropecuária familiar. A área sob influência antrópica corresponde a aproximadamente 794 ha (SANTOS et al., 2002) e o restante com a dominância de Mata Atlântica de Altitude. Na área sob ação antrópica, encontram-se atualmente cinco tipos de uso do solo: capoeira (área de pousio), reflorestamento (sabiá - Mimosa caesalpiniaefolia) e uso agropecuário (capineira e roçado). No enfoque deste trabalho, destacaram-se a área nativa, o reflorestamento e a capoeira em comparação com as áreas de uso agropecuário. A coleta de solo baseou-se num desenho estratificado de amostragem, com combinação fatorial incompleta de estratos, 5 x 4, sendo cinco posições no relevo (topo, ombro, meia encosta, pedimento e várzea) e quatro sistemas de uso do solo (reflorestamento, uso agropecuário, capoeira e Mata Atlântica de altitude). A combinação foi incompleta porque algumas situações de uso não foram encontradas nas cinco posições do relevo. O número de amostras em cada estrato encontra-se na Tabela 1. As posições no relevo deram origem a variações texturais marcantes, motivo pelo qual essa variável foi incorporada ao desenho experimental na análise dos dados.

Em cada ponto amostral georreferenciado, foram retiradas amostras de solo da camada de 0-20 cm de vários pontos numa área de 10 × 10 m e misturadas. Uma vez que essa área amostral $\left(100 \mathrm{~m}^{2}\right)$ foi, pelo menos, duas ordens de magnitude menor que a área representada pela amostra, esta última foi considerada como amostra simples. As amostras foram secas ao ar, passadas em peneira de $2 \mathrm{~mm}$ e analisadas quanto a granulometria, $\mathrm{pH}$, Ca e Mg trocáveis, acidez trocável e P, K e Na extraíveis por Mehlich-1 (EMBRAPA, 1997).

As variáveis quantitativas apresentaram distribuição log-normal e, por esse motivo, foram apresentadas médias geométricas (PARKIN e ROBINSON, 1993). Os atributos do solo foram avaliados, inicialmente, por meio de estatística descritiva: média geométrica, mediana, valores máximo e mínimo e primeiro e terceiro quartis. A análise de variância (ANOVA) foi realizada com as variáveis transformadas, utilizando-se esquema fatorial incompleto $5 \times 4$ (cinco posições no relevo e quatro sistemas de uso) (SAS, 1985). As médias foram comparadas aplicando-se o teste de Tukey a 5\%.

Tabela 1 - Número de amostras compostas de solo, por estrato, em áreas de encosta pedimento, encosta linear e encosta ombro na bacia hidrográfica da represa Vaca Brava, PB.

Table 1 - Number of composed soil samples, for stratus, in hillside areas landscape, linear landscape and shoulder landscape in Vaca Brava Watershed, Paraíba State, Brazil.

\begin{tabular}{|c|c|c|c|c|c|c|}
\hline Cobertura do Solo & Topo & Ombro & Meia Encosta & Pedimento & Várzea & Total \\
\hline Uso agropecuário & 25 & 19 & 129 & 36 & 51 & 260 \\
\hline Mata & 14 & 1 & 37 & 2 & 12 & 66 \\
\hline Reflorestamento (Sabiá) & 02 & 0 & 12 & 2 & 02 & 18 \\
\hline Capoeira & 0 & 4 & 11 & 1 & 0 & 16 \\
\hline Total & 41 & 24 & 189 & 41 & 65 & 360 \\
\hline
\end{tabular}

R. Árvore, Viçosa-MG, v.34, n.2, p.277-285, 2010 


\section{RESULTADOS E DISCUSSÃO}

\section{Análise descritiva}

Os valores de CTC das amostras na bacia hidrográfica da represa Vaca Brava oscilaram entre 1,04 e $10,8 \mathrm{cmol}_{c} \mathrm{dm}^{-3}$, enquanto a faixa de variação do C ficou entre 4,31 - 43,7 $\mathrm{g} \mathrm{kg}^{-1}$ (Tabela 2). Em média, o teor de $\mathrm{N}$ no solo oscilou entre 0,4 e $3,8 \mathrm{~g} \mathrm{~kg}^{-1}$. Essa variação é função da variabilidade do solo e do uso na área.

Com base nos limites do coeficiente de variação (CV) propostos por Warrick e Nielson (1980) para a classificação de propriedades do solo, observa-se, na Tabela 2, que o carbono, o nitrogênio e o cálcio apresentam variação média, enquanto o fósforo mostra alta variação. O fósforo é o que apresenta os maiores valores de CV. Pesquisas de campo têm mostrado a importância do estudo das variações das condições do solo como aspecto fundamental para implementar técnicas agrícolas mais eficientes e rentáveis (FERREIRA et al., 2007;
FRANCO et al., 1995; GARAY e KINDEL, 2001; HIGA e HIGA, 2000; SILVA e CHAVES, 2001). A degradação do solo pode ser avaliada de diversas maneiras. Um dos indicativos usados pode ser a perda de matéria orgânica do solo e, consequentemente, dos nutrientes nela contidos. Entre eles, o N é o mais afetado, já que a matéria orgânica é a sua principal fonte. Nos resultados deste estudo, isso foi evidenciado (Figuras 3 e 4), fato também detectado por Sá et al. (2000).

\section{Efeito do uso do solo e posições do relevo}

No caso do uso do solo (Tabela 3), observou-se que os valores de $\mathrm{C}$ e $\mathrm{N}$ foram mais elevados $(\mathrm{p}<0,05)$ nas áreas cobertas com vegetação nativa (mata), enquanto em $P$ os valores foram maiores $(p<0,05)$ nas áreas agrícolas. Para Galvão et al. (2005), o uso do solo é o fator determinante nas variações observadas, e o uso antrópico propicia maiores quedas nos teores da matéria orgânica do solo, em comparação com o sistema pecuário (pastagens e capineiras).

Tabela 2 - Sumário da estatística descritiva das variáveis analisadas nas áreas estudadas.

Table 2 - Summary of descriptive statistics for variable analyzed in studied areas.

\begin{tabular}{|c|c|c|c|c|c|c|}
\hline Variáveis & $\mathrm{N}$ & Média & Desvio Padrão & Mínimo & máximo & $\mathrm{CV}(\%)$ \\
\hline $\mathrm{pH}\left(\mathrm{H}--_{2} \mathrm{O}\right)$ & 360 & 5,35 & 0,573 & 4,08 & 8,40 & 11 \\
\hline CTC $\left(\mathrm{cmol} \mathrm{kg}^{-1}\right)$ & 360 & 3,50 & 1,74 & 1,04 & 10,8 & 50 \\
\hline $\mathrm{Ca}\left(\mathrm{cmol}_{\mathrm{c}} \mathrm{kg}^{-1}\right)$ & 360 & 1,78 & 0,959 & 0,280 & 5,99 & 54 \\
\hline $\operatorname{Mg}\left(\mathrm{cmol}^{\mathrm{c}} \mathrm{kg}^{-1}\right)$ & 360 & 1,13 & 0,740 & 0,194 & 4,54 & 66 \\
\hline $\mathrm{K}\left(\mathrm{cmol}_{\mathrm{c}} \mathrm{kg}^{-1}\right)$ & 360 & 0,186 & 0,147 & 0,010 & 0,887 & 79 \\
\hline $\mathrm{P}\left(\mathrm{mg} \mathrm{kg}^{-1}\right)$ & 360 & 5,55 & 7,91 & 0,397 & 49,9 & 142 \\
\hline $\mathrm{N}\left(\mathrm{g} \mathrm{kg}^{-1}\right)$ & 360 & 1,24 & 0,70 & 0,395 & 3,83 & 56 \\
\hline $\mathrm{C}\left(\mathrm{g} \mathrm{kg}^{-1}\right)$ & 360 & 14,9 & 8,21 & 4,31 & 43,7 & 54 \\
\hline $\mathrm{H}+\mathrm{Al}\left(\mathrm{cmol}_{\mathrm{c}} \mathrm{kg}^{-1}\right)$ & 360 & 0,316 & 0,407 & 0,025 & 2,90 & 13 \\
\hline $\mathrm{S}\left(\mathrm{cmol}_{\mathrm{c}} \mathrm{kg}^{-1}\right)$ & 360 & 3,18 & 1,64 & 0,645 & 9,23 & 52 \\
\hline ds $\left(\right.$ g. dm $\left.{ }^{-3}\right)$ & 360 & 1,18 & 0,144 & 0,860 & 1,492 & 12 \\
\hline
\end{tabular}

СтC Capacidade de troca de cátions; s Soma de bases; ds densidade aparente; e CV: coeficiente de variação

Tabela 3 - Efeito do uso do solo nos teores médios ( \pm erro-padrão) de carbono total, nitrogênio total e P Mehlich-1 dos solos da bacia hidrográfica da represa Vaca Brava, PB.

Table 3 - Effect of soil used in average ( \pm error standard) of total carbon, total nitrogen and P Mehlich-1 of soil the Vaca Brava watershed, Paraíba State, Brazil.

\begin{tabular}{|c|c|c|c|}
\hline Uso atual & C total & $\mathrm{N}$ total & P Mehlich-1 \\
\hline & $\longrightarrow$ & 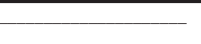 & mg.kg-1 \\
\hline Mata $(n=64)$ & $27,42(0,91) a$ & $2,34(0,08) a$ & $2,38(0,13) b$ \\
\hline Reflorestamento - Sabiá (n = 18) & $16,94(1,55) b$ & $1,34(0,12) b$ & $2,51(0,32) b$ \\
\hline Capoeira $(n=18)$ & $15,27(1,41) b$ & $1,24(0,11) b$ & $1,75(0,31) b$ \\
\hline Uso Agropecuário (n = 260) & $11,46(0,56) \mathrm{c}$ & $0,71(0,03) \mathrm{c}$ & $8,02(1,17)$ a \\
\hline
\end{tabular}

Letras diferentes na coluna diferem entre si, a 5\% de probabilidade, pelo teste de Tukey. 
Segundo Oliveira et al. (1999), o conhecimento dos valores e as localizações das áreas onde estão concentrados os maiores e, ou, menores valores de determinada variável são importantes para o planejamento do manejo da fertilidade do solo, tanto na agricultura convencional quanto na agricultura de precisão. Na variável carbono orgânico do solo, podem-se observar as glebas mais críticas em relação aos baixos teores. Fatos esses semelhantes para o nitrogênio e o fósforo, em que o comportamento da distribuição desses elementos na área estudada foi variável, sinalizando que o manejo do solo seja diferenciado.

Os maiores teores de matéria orgânica foram encontrados em solos sob vegetação de mata em relação às áreas agrícolas. O sistema agropecuário produziu declínio significativo na concentração de C e N (Tabela 4). Essa constatação é frequente na literatura (TIESSEN et al., 1992) e resulta de maiores taxas de aporte de resíduos orgânicos ao solo e menores taxas de decomposição pela ausência de revolvimento em relação às áreas agrícolas (ALVARENGAe DAVIDE, 1999). Fraga e Salcedo (2004), estudando as concentrações de C e N em áreas cultivadas, verificaram que esses elementos foram $50 \%$ menores $(p<0,05)$ do que os encontrados nos solos sob Caatinga preservada.

Os maiores teores de Ca e Mg e de CTCE ressaltaram a contribuição da matéria orgânica para a capacidade de troca desses solos, fato constatado em outros trabalhos (MENEZES e SALCEDO, 1999; MENEZES et al., 2002). Os processos mais importantes responsáveis pela perda da fertilidade do solo são a erosão e a retirada de nutrientes pela colheita dos produtos agropecuários (MENEZES e SAMPAIO, 2000).

O efeito imediato depois da queima é o desaparecimento da serrapilheira e incremento do $\mathrm{pH}$ devido às cinzas. Como resultado, ocorre incremento transitório das condições de fertilidade do solo, já que o pH mais elevado favorece a taxa de troca de cátions

Tabela 4-Médias geométricas de atributos determinados em amostras classificadas pela posição no relevo e uso da terra. Table 4 - Geometric averages of attributes determined in samples classified for position in relief and soil used.

\begin{tabular}{|c|c|c|c|c|c|c|c|c|c|}
\hline \multirow[t]{2}{*}{ Uso do Solo } & $\mathrm{C}$ & $\mathrm{N}$ & \multirow{2}{*}{$\begin{array}{c}\mathrm{P}^{*} \\
\mathrm{mg} \mathrm{kg}\end{array}$} & \multirow[t]{2}{*}{$\mathrm{pH}_{\mathrm{H} 2 \mathrm{O}}$} & $\mathrm{Ca}$ & $\mathrm{Mg}$ & $\mathrm{K}$ & $\mathrm{Na}$ & $\mathrm{H}+\mathrm{Al}$ \\
\hline & \multicolumn{2}{|c|}{$-\mathrm{g} \mathrm{kg}^{-1} \longrightarrow$} & & & \multicolumn{5}{|c|}{$\mathrm{cmol}_{\mathrm{c}} \mathrm{kg}^{-1}$} \\
\hline \multicolumn{10}{|c|}{ Várzea } \\
\hline Mata (n: 12) & 29,8 a & $2,54 \mathrm{a}$ & 3,48 & 5,15 a & 2,99 a & 2,45 a & $0,05 \mathrm{~b}$ & $0,04 \mathrm{~b}$ & $0,22 \mathrm{a}$ \\
\hline Uso agropecuário (n:51) & $12,1 b$ & $0,99 \mathrm{~b}$ & 6,92 & 5,40 a & $1,72 \mathrm{~b}$ & $1,23 \mathrm{~b}$ & 0,15 a & 0,21 a & $0,17 \mathrm{a}$ \\
\hline Reflorestamento - Sabiá (n: 02) & 12,1 & 1,00 & 2,33 & 4,94 & 1,58 & 0,73 & 0,11 & 0,11 & 0,24 \\
\hline \multicolumn{10}{|c|}{ Topo } \\
\hline Mata (n: 14) & 23,6 a & 1,96 a & 1,97 & $4,77 \mathrm{~b}$ & $1,54 \mathrm{a}$ & $1,08 \mathrm{a}$ & 0,18 a & 0,09 a & $0,53 \mathrm{a}$ \\
\hline Uso agropecuário (n:25) & $11,35 \mathrm{~b}$ & $0,89 \mathrm{~b}$ & 2,10 & 5,50 a & 1,52 a & 0,80 a & 0,15 a & $0,03 \mathrm{~b}$ & $0,26 \mathrm{~b}$ \\
\hline Reflorestamento - Sabiá (n:02)\# & 12,3 & 1,08 & 1,99 & 5,46 & 1,71 & 1,08 & 0,21 & 0,04 & 0,12 \\
\hline \multicolumn{10}{|c|}{ Ombro } \\
\hline Mata (n: 01)\# & 24,5 & 1,84 & 1,32 & 4,70 & 2,09 & 1,57 & 0,19 & 0,04 & 0,08 \\
\hline Uso agropecuário (n:19) & 11,3 & 0,93 & 1,97 & 5,32 & 1,86 & 1,04 & 0,16 & 0,03 & 0,33 \\
\hline Capoeira (n: 04)\# & 18,7 & 1,62 & 1,92 & 5,10 & 1,87 & 1,36 & 0,26 & 0,09 & 0,18 \\
\hline \multicolumn{10}{|c|}{ Meia encosta } \\
\hline Mata (n: 37) & 28,8 a & 2,48 a & 2,14 & $4,95 \mathrm{ab}$ & 2,82 a & $1,88 \mathrm{a}$ & $0,26 \mathrm{ab}$ & 0,12 a & $0,68 \mathrm{a}$ \\
\hline Uso agropecuário (n:129) & $11,7 \mathrm{c}$ & $0,97 \mathrm{~b}$ & 2,17 & $5,52 \mathrm{ab}$ & 1,66 bc & $1,04 \mathrm{~b}$ & $0,17 \mathrm{~b}$ & $0,05 \mathrm{c}$ & $0,31 \mathrm{~b}$ \\
\hline Reflorestamento - Sabiá (n: 12) & $16,4 \mathrm{~b}$ & $1,31 \mathrm{~b}$ & 2,18 & $5,09 \mathrm{ab}$ & $1,80 \mathrm{bc}$ & $0,95 \mathrm{~b}$ & 0,29 a & 0,12 a & $0,48 \mathrm{ab}$ \\
\hline Capoeira (n: 11) & $18,0 \mathrm{~b}$ & $1,44 \mathrm{~b}$ & 2,03 & $4,91 \mathrm{~b}$ & $1,24 \mathrm{c}$ & $1,09 \mathrm{~b}$ & $0,23 \mathrm{ab}$ & $0,08 \mathrm{~b}$ & $0,48 \mathrm{ab}$ \\
\hline \multicolumn{10}{|c|}{ Pedimento } \\
\hline Mata (n: 02)\# & 16,4 & 1,49 & 1,99 & 5,18 & 3,11 & 1,11 & 0,11 & 0,16 & 0,08 \\
\hline Uso agropecuário (n:129) & 8,78 & 0,70 & 2,13 & 5,75 & 1,51 & 0,76 & 0,14 & 0,04 & 0,17 \\
\hline Reflorestamento - Sabiá (n:02)\# & 14,8 & 1,25 & 2,19 & 4,98 & 1,59 & 0,80 & 0,18 & 0,03 & 0,07 \\
\hline Capoeira (n: 01)\# & 8,92 & 0,73 & 1,13 & 5,06 & 0,79 & 0,25 & 0,18 & 0,03 & 0,38 \\
\hline
\end{tabular}

\# Estes usos não foram incluídos na análise estatística devido ao reduzido número de observações.

*Mediana.

Médias seguidas pela mesma letra na coluna não diferem significativamente $(p<0,05)$ entre si, pelo teste de Tukey.

R. Árvore, Viçosa-MG, v.34, n.2, p.277-285, 2010 
e aumentam os teores de P, K e Mg. No entanto, esses teores não são suficientes para a nutrição das plantas e, geralmente, no decorrer dos anos voltam às concentrações similares às das florestas de origem. Também foi observado aumento da densidade nas camadas mais superficiais do solo, o qual é atribuído às mudanças do sistema radicular, ao pisoteio do gado e à destruição do complexo argila/matéria orgânica, os quais se dispersam em partículas finas, causando a obstrução dos microporos (DIEZ et al., 1997; MARTINS et al., 1991; MORAES et al., 1996).

Os valores mais elevados de K nas áreas agrícolas podem ser justificados em função de alguns produtores usarem adubação orgânica (PETERSEN et al., 2002), principalmente esterco bovino, que é fonte desses nutrientes (SAMPAIO et al., 1985). Com relação ao relevo, foram comparadas estatisticamente amostras provenientes de áreas com uso agropecuário, mata, capoeira e reflorestamento (sabiá). Com poucas exceções (Ca, S e P), em que as amostras provenientes de áreas agrícolas foram pouco maiores, os atributos analisados não diferiram entre si quanto ao uso da terra. O pedimento é caracterizado por ganhos e perdas de sedimentos, o que acaba contribuindo para essa uniformidade das propriedades químicas entre os usos do solo (BERTONI e LOMBARDI NETO, 1999).

\section{CONCLUSÕES}

1. As propriedades químicas e físicas mostraram-se influenciadas pelo uso do solo, com aumento nos teores de $\mathrm{N}$ e C no sentido agricultura-floresta, como era esperado, enquanto o fósforo disponível à variabilidade ocorreu no sentido contrário, em função de algum tipo de fertilização utilizada pelos produtores. Os solos da bacia hidrográfica da represa Vaca Brava possuem baixa fertilidade, necessitando de manejo diferenciado quando utilizado para fins agropecuários.

2. A maior quantidade de matéria orgânica incorporada ao solo pela decomposição em reflorestamento foi decorrente da maior qualidade nutricional do folhiço do reflorestamento e representada pela menor relação $\mathrm{C} / \mathrm{N}$.

3. A maior quantidade de material foliar acumulada nas camadas superficiais na área sob reflorestamento, o maior teor e estoque de nitrogênio no folhiço, a menor relação $\mathrm{C} / \mathrm{N}$ do folhiço e a maior quantidade de matéria orgânica incorporada ao solo pela decomposição em reflorestamento refletiram a grande contribuição em matéria orgânica e nitrogênio que essa espécie fornece ao solo, evidenciando sua maior eficiência em reconstituir os horizontes orgânicos do solo.

4. Os maiores teores de carbono, nitrogênio e nutrientes no reflorestamento e a alta correlação que eles apresentaram demonstraram a dependência da fertilidade do solo à matéria orgânica incorporada.

5. Em relação à matéria orgânica e aos demais atributos do solo, não foram encontrados os mesmos teores obtidos na mata nativa, indicando que o tempo de uso agropecuário não foi suficiente para restabelecer a fertilidade do solo superficial; pelo contrário, levou o solo à degradação.

\section{AGRADECIMENTOS}

Ao CNPq (Projeto - Agricultura Familiar), ao Programa de Pós-Graduação em Tecnologias Energéticas e Nucleares - DEN/UFPE e ao IAI (InterAmerican Institute for Global Change-CRN 001), pelo financiamento deste trabalho.

\section{REFERÊNCIAS}

AIDAR, M. P. M.; JOLY, C. A. Dinâmica da produção e decomposição da serrapilheira de araribá (Centrolobium tomentosum Guill. ex Benth. - Fabaceae) em uma mata ciliar, Rio JacaréPepira, São Paulo. Revista Brasileira de Botânica, v.26, n.1, p.193-202, 2003.

ALVARENGA, M. I. N.; DAVIDE, A. C. Características físicas e químicas de um Latossolo Vermelho-escuro e a sustentabilidade de agroecossistemas. Revista Brasileira de Ciência do Solo, v.23, n.4, p.933-942, 1999.

ALVARenga, M. I. N. Propriedades físicas, químicas e biológicas de um Latossolo Vermelho-Escuro em diferentes ecossistemas. 1996. 211f. Tese (Doutorado em Fitotecnia) - Universidade Federal de Lavras, Lavras, 1996.

ARATO, H. D.; MARTINS, S. V.; FERRARI, S. H. S. Produção e decomposição de serrapilheira em um sistema agroflorestal implantado para recuperação de área degradada em Viçosa-MG. Revista Árvore, v.27, p.715-721, 2003.

R. Árvore, Viçosa-MG, v.34, n.2, p.277-285, 2010 
BERTALOT, M. J. A. et al. Retorno de nutrientes ao solo via deposição de serrapilheira de quatro espécies leguminosas arbóreas na região de Botucatu-SP. Scientia Forestalis, v.65, p.219227, 2004.

CHAVES, I. B. Erosividade das chuvas da microrregião homogênea n. 98 Estado da Paraíba. 1977. 78f. Dissertação (Mestrado em...) - Escola Superior de Agricultura Luiz de Queiroz, Piracicaba, 1977. 78p.

DIEZ, J. A. et al. Effect of fallow land, cultivated pasture and abandoned pasture on soil fertility in two deforest Amazonian regions. Scientia Agricola, v.54, n.1, p.45-52, 1997.

\section{EMPRESA BRASILEIRA DE PESQUISA}

AGROPECUÁRIA - EMBRAPA. Centro Nacional de Pesquisas de Solos. Sistema brasileiro de classificação de solos. Brasília: Embrapa Produção de Informação; Rio de Janeiro: Embrapa Solos, 1999. 412p.

\section{EMPRESA BRASILEIRA DE PESQUISA} AGROPECUÁRIA - EMBRAPA. Manual de métodos de análise de solos. Rio de Janeiro: 1979. 255p.

FERREIRA, R. L. C. et al. Deposição e acúmulo de matéria seca e nutrientes em serrapilheira em um bosque de sabiá (Mimosa caesalpiniifolia Benth.). Revista Árvore, v.31, n.1, p.7-12, 2007.

FERREIRA, C. A. et al. Deposição de material orgânico e nutrientes em plantios de E. grandis em diferentes regimes de adubação. Boletim de Pesquisa, v.43, p.75-86, 2001.

FIGUEIREDO FILHO, A. et al. Avaliação estacional da deposição da serrapilheira em uma floresta ombrófila mista localizada no sul do estado do Paraná. Ciência Florestal, v.13, p.11-18, 2003.

FRAGA, V. S.; SALCEDO, I. H. Declines of organic nutrient pools in tropical semi- arid soils under subsystems farming. Soil Science Society America Journal, v.68, n.1, p.215224, 2004.

R. Árvore, Viçosa-MG, v.34, n.2, p.277-285, 2010

\section{R. Árvore, Viçosa-MG, v.34, n.2, p.277-285, 2010}

FRANCO, A. A. et al. Uso de leguminosas florestais noduladas e micorrizadas como agentes de recuperação e manutenção da vida do solo: um modelo tecnológico. In: ESTEVES, F., (Ed.) Oecologica Brasiliensis: estrutura, funcionamento e manejo de ecossistemas. Rio de Janeiro: 1995. p.459-467.

GARAY, I. et al. Comparação da matéria orgânica e de outros atributos do solo entre plantações de Acacia mangium e Eucalyptus grandis. Revista Brasileira de Ciência do Solo, v.27, n.4, p.705-712, 2003.

GARAY, I.; KINDEL, A. Diversidade funcional em fragmentos de Floresta Atlântica. Valor indicador das formas de húmus florestais. In: GARAY, I. \& DIAS, B., (Orgs.) Conservação da biodiversidade em ecossistemas tropicais: avanços conceituais e revisão de novas metodologias de avaliação e monitoramento. Petrópolis: Vozes, 2001. p.350-368.

HIGA, A. R.; HIGA, R. C. V. Indicações de espécies para o reflorestamento. In: GALVÃO, A. P. M., (Org.) Reflorestamento de propriedades rurais para fins produtivos e ambientais. Um guia para ações municipais e regionais. Brasília: Embrapa Comunicação para Transferência de Tecnologia e Colombo/PR: Embrapa Florestas, 2000. p.101-124.

GALVÃO, S. R. S.; SALCEDO, I. H.; SANTOS, A. C. Frações de carbono e nitrogênio em função da textura, do relevo e do uso do solo na microbacia do agreste em Vaca Brava (PB). Revista

Brasileira de Ciência do Solo, v.29, n.5, p.955-962, 2005.

KINDEL, A. et al. Efeito do extrativismo seletivo de espécies arbóreas da Floresta Atlântica de Tabuleiros na matéria orgânica e outros atributos do solo. Revista Brasileira de Ciência do Solo, v.23, NUMERO, p.465-474, 1999.

KINDEL, A.; GARAY, I. Caracterização de ecossistemas da Floresta Atlântica de Tabuleiros por meio das formas de húmus. Revista Brasileira de Ciência do Solo, v.25, NUMERO, p.551-563, 2001.

KINDEL, A.; GARAY, I. Humus form in ecosystems of the Atlantic Forest, Brazil. Geoderma, v.108, n.1, p.101-118, 2002. 
KURZATKOWSKI, D. et al. Litter decomposition, microbial biomass and activity of soil organisms in three agroforestry sites in central Amazonia. Nutrient Cycling in Agroecosystems, v.69, p.257-267, 2004.

LIMA, W. P. O reflorestamento com eucalipto e seus impactos ambientais. São Paulo: Artpress, 1987. 114p.

MARTINS, P. F. S. et al. Consequences of clearing and tillage on the soil of a natural Amazonian ecosystem. Forest Ecology and Management, v. 38, p. 273-282, 1991.

MORAES, J. F. L. et al. Soil properties under Amazon Forest and changes duo pasture installation in Rondonia, Brazil. Geoderma, v. 70, n.1, p. 63-81, 1996.

OLIVEIRA, J. J. et al. Variabilidade espacial de propriedades químicas em um solo salino-sódico. Revista Brasileira de Ciência do Solo, v.23, n.4, p.783-789, 1999.

PAINE, L. K.; RIBIC, C. A. Comparison of riparian plant communities under four land management systems in Southwestern Wisconsin.

Agriculture Ecosystems Environment, v.92, n.1, p.93-105, 2002.

PARKIN, T. B.; ROBINSON, J. A. Statistical evaluation of median estimators for lognormally distributed variables. Soil Science Society of America Journal, v.57, p.317-323, 1993.

SÁ, J. C. M. et al. Plantio direto: recupera a matéria orgânica do solo e reduz a emissão de $\mathrm{CO}_{2}$ para a atmosfera. Revista Plantio Direto, v.59, n.1, p.41-45, 2000.

RODRIGUES, L. A. et al. Efeitos de solos e topografia sobre a distribuição de espécies arbóreas em um fragmento de floresta estacional semidecidual, em Luminárias, MG. Revista Árvore, v.31, n.1, p.25-35, 2007.

SANTOS, A. C.; SALCEDO, I. H.; CANDEIAS, A. L. B. Relação entre o relevo e as classes texturais do solo na microbacia hidrográfica de Vaca Brava, PB. Revista Brasileira de Cartografia, v.54, n.1, p.86-94, 2002.

SAS Institute. User guide: Statistics. 5.ed. Cary: 1985. 483p.
SILVA, P. C. M.; CHAVES, L. H. G. Avaliação e variabilidade espacial de fósforo, potássio e matéria orgânica em Alissolos. Revista Brasileira de Engenharia Agrícola Ambiental, v.5, n.3, p.431-436, 2001.

SCHUMACHER, M. V. et al. Produção de serrapilheira em uma floresta de Araucária angustifolia (Bertol) Kuntze no município de Pinhal Grande-RS. Revista Árvore, v.28, n.1, p.29-37, 2004.

SCHUMACHER, M. V. et al. Retorno de nutrientes via deposição de serrapilheira em um povoamento de Acácia-Negra (Acacia mearnsii De Wild) no Estado do Rio Grande do Sul. Revista Árvore, v.27, NUMERO, p.791-798, 2003.

SILVA, J. R. C. Erosão e produtividade do solo no semi-árido. In: OLIVEIRA, T.S., et al., (Eds.) Agricultura, sustentabilidade e o semi-árido. Viçosa, MG: Sociedade Brasileira de Ciência do Solo/ Fortaleza: Universidade Federal do Ceará, 2000. p.170-213.

SILVA, T. O. Adubação orgânica da batata (Solanum tuberosum L.) com esterco e/ou Crotalaria juncea L. em um Neossolo Regolítico. 2004. 47f Dissertação (Mestrado em Tecnologias Energéticas e Nucleares) - Universidade Federal de Pernambuco, Recife, 2004..

THEODORO, V.C.A. Caracterização de sistemas de produção de café orgânico, em conversão e convencional. 1999. 214f. Dissertação (Mestrado em Fitotecnia) - Universidade Federal de Lavras, Lavras, 1999.

TIESSEN, H.; SALCEDO, I. H.; SAMPAIO, E. V. S. B. Nutrient and soil organic matter dynamics under shifting cultivation in semi-arid northeastern Brazil. Agriculture,. Ecosystems \& Environment, v.38, n.3, p.139-151, 1992.

WEID, J. M. von der. Conceitos de sustentabilidade e sua aplicação nos modelos de desenvolvimento agrícola. In: ALVAREZ V., V.H.; FONTES, L.E.F.; FONTES, M.P.F. O solo nos grandes domínios morfo-climáticos do Brasil e o desenvolvimento sustentado. Viçosa, MG: SBCS/UFV/DPS, 1996. p.353-366.

R. Árvore, Viçosa-MG, v.34, n.2, p.277-285, 2010 